\title{
Neurocognitive profile of patients with continuous flow Left Ventricular Assist Device
}

\section{Profilo neurocognitivo dei pazienti con LVAD a flusso continuo}

\author{
David Simoni, Martina Rafanelli, Andrea Ungar, Enrico Mossello, \\ Niccolò Marchionni, Samuele Baldasseroni
}

\begin{abstract}
D. Simoni, M. Rafanelli, A. Ungar, E. Mossello, N. Marchionni, S. Baldasseroni. Neurocognitive profile of patients with continuous flow left ventricular assist device.

The increase of severe heart failure and the consequent reduction of the organ availability for transplantation has led to, in recent years, the introduction of the LVAD as replacement therapy to heart transplantation. Severe Heart Failure patients show cognitive deficits in various domains especially in executive functions, memory and speed of proceedings, due to different neurophysiopathological processes including chronic hypoperfusion and subsequent damage to hippocampal and para-hippocampal cortical areas. It is also known that these deficits improve after heart transplantation. We carried out a literature review selecting studies that analyzed the cognitive changes in patients with severe heart
\end{abstract}

failure after implantation of the Continuous Flow Left Ventricular Assist Device. According to the inclusion criteria, we selected four studies since 2005 that presented a comprehensive neurocognitive assessment. The results show that the cognitive profile, with the implantation of LVAD improves in memory and executive domains, and this improvements results stable in short- medium time. The effects would also be independent of the type of flow produced by the device (pulsatile vs continuous). We believe that further studies are required to explore the relationship between LVAD and cognitive function in severe heart failure.

Keywords: "ventricular assist device", cognitive, neurocognitive, neuropsychology.

Monaldi Arch Chest Dis 2014; 82: 75-79.

Research Unit of Aging, Department of Clinical and Experimental Medicine Azienda Ospedaliero-Universitaria Careggi, Florence.

Corresponding author: David Simoni; Research Unit of Aging, Department of Clinical and Experimental Medicine, University of Florence; Viale Pieraccini, 6; Firenze, Italy; Tel: 3383055538; E-mail address: david.simoni@unifi.it

\section{Introduction}

For over thirty years the lack of an effective therapy for the treatment of End-Stage Heart Failure (ESHF) has led to the development of a constant research in the field of ventricular assist devices. The first Left Ventricular Assist Device (LVAD) was developed during the 1980s as "Bridge Therapy" (BT) in patients with ESHF waiting for heart transplantation. Yet the use of LVADs has significantly increased as "Destination Therapy" (DT) since 2002, especially with the introduction of Continuous-Flow LVAD (CF-LVAD) [1]. Several studies have shown less CF-LVAD-related complications, compared to Pulsatile-Flow LVAD (PF-LVAD), maintaining an adequate systemic perfusion [2].

In 2012, the European Society of Cardiology published guidelines for the use of LVAD therapy. These criteria for LVAD implantation included patients who have New York Heart Association class IV symptoms for at least 60 days under optimal heart failure therapy, or need inotropic support for heart failure treatment; display a left ventricular ejection fraction under $25 \%$; have a peak oxygen consumption of $<12-14 \mathrm{~mL} /(\mathrm{kg} \times \mathrm{min})$; or show a documented inability to be weaned off intravenous inotropic therapy. Patients selected for DT usually have contraindications for heart transplantation [3].

In general LVAD treatment is not devoid of risks and it is associated with an increased stroke risk (5-12\% of the cases), mainly in the first 48 hours following the implantation. Some studies have suggested that the restoration of a normal cerebral blood flow, in patients with a previously reduced cardiac output, might overwhelm cerebral blood flow autoregulation mechanisms and contribute to the onset of a post-operative neurological complication, although no definitive evidence still supports this hypothesis [4]. In this regard, various studies have confirmed that continuous axial flow would allow a lower incidence of hemorrhagic strokes compared to pulsatile one [5], while supporting satisfactorily the systemic perfusion. Letsou et al [6] showed that an adequate end-organ perfusion was maintained in subjects implanted with the Jarvik $2000 \circledR$ for over six months. Similarly, in a small clinical series end-organ function did not deteriorate after one year with axial flow LVAD [7]. Kamdar et al [2] have confirmed that continuous axial flow would be better than pulsatile one in supporting end-organ perfusion and reducing adverse events. 
Cognitive performances of subjects with CF-LVAD have not been satisfactorily evaluated. Numerous studies have observed the association between heart diseases and cognitive decline [8]. Neuropsychological tests, commonly used for the assessment of patients with HF, revealed the presence of cognitive impairment after heart transplantation, showing that cognitive profile was significantly influenced by preprocedural disease severity [9]. Low cardiac output or ischemic stress due to prolonged hypoperfusion [10] have been identified among the possible causes of cognitive impairment in ESHF patients. From a neuro-anatomical point of view, patients with ESHF show neuronal loss in the mesial-temporal hippocampal area and para-hippocampal regions, particularly sensitive to hypoxia and responsible for memory functioning. Neuroimaging studies shows signs of brain injury in several regions involved in cognitive functioning, including hippocampus, mammillary bodies, corpus callosum, basal ganglia, and frontal regions [11, 12]. A good cognitive functioning has a primary role in care of patients with ventricular devices, as they are actively involved in their medical management (e.g. anticoagulants, machine management), as well as in the interaction with the heart-team. One of the prerequisites for use of LVAD as DT, in addition to cognitive ability, is that exercise capacity was adequate for daily life activities, because it could improve the quality of life of these patients [13]. Exercise training for LVAD patient, as part of a multidisciplinary cardiac rehabilitation program, is effective and safe improving quality of life [14]. Intensive cardiological rehabilitation program, during the first phase of LVAD-implantation, allows, relatively soon to return at home with adequate clinical and functional stabilization, and necessary education for device self-management [15].
The purpose of this review is to analyze the scientific production since the CF-LVAD as BT or DT have been introduced, aimed at highlighting the changes in neuropsychological profile of ESHF patients supported by CF-LVAD.

\section{Methods of analysis}

We searched for all the papers published from January 2005 to December 2014 with different search engines, such as PubMed, PsycINFO, Science Direct, EBSCO, written in English language, regarding subjects implanted with any model of CF-LVAD, in which the cognitive profile has been analyzed by means of a comprehensive neuropsychological battery or by neurophysiological assessment of cognitive function. Studies adopting brief cognitive testing (e.g. Mini Mental State Examination) as the only assessment method were excluded, because of possible bias owing to ceiling effect, especially in this population. The keywords "ventricular assist device" AND ("cognitive" OR "neurocognitive" OR "neuropsychology") were used for literature search.

\section{Nurocognitive profile after LVAD implantation: present data}

We have selected four studies which have analyzed the neurocognitive profile of subjects with ESHF, who underwent LVAD implantation. Among the studies analyzed, one has used the P300 EventRelated Potentials (P300/ERP) analysis, three a comprehensive neuropsychological battery.

Zimpfer at al [16] (Table 1) have conducted a prospective study on $29 \mathrm{ESHF}$ patients (11 with $\mathrm{CF}$ - LVAD, mean age 54) compared to a age-matched control group of healthy subjects, aimed at comparing the effects of pulsatile and continuous flow

\begin{tabular}{|c|c|c|c|}
\hline Authors & Sample Caracteristics & Neurocognitive Assessment & Results \\
\hline $\begin{array}{l}\text { Zimpfer et } \\
\text { al } 2006\end{array}$ & $\begin{array}{l}18 \text { with PF-LVAD (mean age } 50+/- \\
10 ; 94 \% \text { male); LVEF } 20 \%+/-5 \\
11 \text { with CF-LVAD (mean age } 56+/- \\
15 ; 100 \% \text { male); LVEF } 20 \%+/-6\end{array}$ & Cognitive P300 Evoked Potentials & $\begin{array}{l}\downarrow \mathrm{P} 300 \text { peak latency in post } \\
\text { implantation }(\mathrm{p}=0.007), 8 \mathrm{w} \mathrm{FU} \\
(\mathrm{p}=0.022), 12 \mathrm{w} \mathrm{FU}(\mathrm{p}<0.0001)\end{array}$ \\
\hline $\begin{array}{l}\text { Petrucci et } \\
\text { al, } 2009\end{array}$ & $\begin{array}{l}93 \text { (mean age } 50+/-14 ; 75 \% \text { male); } \\
\text { LVEF } 16 \%+/-7\end{array}$ & $\begin{array}{l}\text { Visual spatial perception; Auditory } \\
\text { Memory; Visual Memory; Executive } \\
\text { Function; Language; Processing Speed }\end{array}$ & $\begin{array}{l}\uparrow \text { Visual memory }(\mathrm{T} 0-\mathrm{T} 1 \\
\mathrm{p}=0.004) \text { T0-T2 } \mathrm{p}<0.001) \\
\uparrow \text { Executive Function T0-T1 } \\
\mathrm{p}=0.0001) \text { T0-T2 } \mathrm{p}=0.007)\end{array}$ \\
\hline $\begin{array}{c}\text { Petrucci et } \\
\text { al, } 2012\end{array}$ & $\begin{array}{l}96 \text { with CF-LVAD (mean age } 61+/- \\
13 ; 73 \% \text { male); LVEF } 16.9 \%+/-5.7 \\
30 \text { PF-LVAD (mean age } 57+/-12 \text { : } \\
90 \% \text { male); LVEF } 16.8+/-5\end{array}$ & $\begin{array}{l}\text { Visual spatial perception; Auditory } \\
\text { Memory; Visual Memory; Executive } \\
\text { Function; Language; Processing Speed }\end{array}$ & $\begin{array}{l}\text { Tall domain tested in CF-LVAD } \\
\text { in post-implantation; } \\
\uparrow \text { Memory domain in PF-LVAD }\end{array}$ \\
\hline $\begin{array}{l}\text { Mapelli et } \\
\text { al, } 2014\end{array}$ & $\begin{array}{l}19 \text { with CF-LVAD (mean age } 60.4 \\
+/-10 ; 90 \% \text { male) }\end{array}$ & $\begin{array}{l}\text { Attention; memory; Comprehension; } \\
\text { Executive Functions; } \\
\text { Perception: Praxis ability }\end{array}$ & $\begin{array}{l}\uparrow m e m o r y ~ p o s t-i m p l a n t a t i o n \\
\text { (story recall TO-T2 and T1-T2 } \\
\mathrm{p}=0.009 ; \text { interference memory } \\
(\mathrm{T} 0-\mathrm{T} 2 \mathrm{p}=0.039) ;= \\
\text { other cognitive domain }\end{array}$ \\
\hline
\end{tabular}

PF-LVAD: Pulsatile Flow-Left Ventricular Assist Device: CF-LVAD: Continuous Flow - Left Ventricular Assist Device; LVEF: Left Ventricular Ejection Fraction. 
on the neurocognitive function through P300/ERP analysis. P300/ERP are the result of the activation of a widespread neural network by auditory stimulation and explore the functioning of associative cortical areas and hippocampus, therefore being considered a marker of general neurocognitive function. In the cited study patients were examined both in the pre-procedural phase and after 8 to 12 weeks of follow-up. Before the device implantation, the peak latency of P300 was increased in experimental sample, but there was a significant reduction after 8 weeks $(p=0.022)$ and a further significant change after 12 weeks $(\mathrm{p}<0.0001)$, indicating a progressive improvement of neurocognitive function. Authors found that the type of LVAD flow did not affect the neurocognitive improvement observed after the implantation, and that a complete normalization was not observed in either of the groups. Moreover the neurophysiological improvement after 12 weeks was directly and significantly associated with the increase of cardiac index measured with cardiac catheterization $(\mathrm{R}=0.52, \mathrm{p}=0.008)$.

Petrucci et al [17] (Table 1) have conducted a prospective not-randomized study on 93 patients (mean age 50) in order to propose the neuropsychological examination as part of the safety and efficacy evaluation of CF-LVAD used as BT. The neuropsychological assessment was conducted at 1,3 and 6 months after LVAD implantation, with 23 patients completing the entire follow-up. The $51 \%$ of the patients had idiopathic dilated cardiomyopathy, the $41 \%$ had ischemic cardiopathy. Visual-spatial perception was assessed with the Clock Drawing Test and WAIS III BD - Block Design, memory with the Logical Memory and Visual Reproduction Test (WAIS III LM and VR), executive functions with Trail Making Test form A and B. The data showed that there was a significant improvement between one month and three months $(\mathrm{p}<0.05)$ and between one and six months in visual memory and executive function domains. There was no decline over time in any of the cognitive function examined.

In 2012, the same authors [18] (Table 1) have conducted a study on 126 subjects to analize the cognitive performance of patients with $\mathrm{CF}$ or $\mathrm{PF}$ LVADs as DT during a 2 years follow-up. Data were collected in a sub-group of patients enrolled in the HeartMate II DT Trial [5]. The neurocognitive assessments were performed at 1,3,6,12 and 24 months after LVAD implantation. The sample included two groups, 96 subjects who received CFLVAD (mean age 61) and 30 who received PFLVAD (mean age 57), which underwent the same neuropsychological battery of the previously cited study [14]. There was significant improvement in all studied cognitive domains over time, although only 36 subjects, all in the CF-LVAD group, completed 24-month follow-up. Cognitive changes for CF-LVAD and PF-LVAD groups was similar. There was a significant cognitive improvement between one and three months, with a trend to a further improvement 6 months after the implantation and a good maintenance of cognitive function until the end of follow-up. As expected advanced age had an overall significant inverse effect, with younger patients showing a better cognitive performance. These results seem to confirm that the cognitive domains improve independently from LVAD flow and moreover show a positive effects in long-term follow-up, although only a limited group of patients could complete all assessments.

Recently Mapelli et al [19] (Table 1), have analyzed the neuropsychological profile evolution in 10 ESHF patients (mean age 61) both before and 2, 5 and 16 months after LVAD implantation. The neuropsychological battery included memory domain (Digit Span, immediate and delayed prose recall memory, interference memory memory domain), executive and attention domain (Trail Making Test $\mathrm{A}$ and $\mathrm{B}$, spontaneuos drawing, copy drawing, clock drawing), abstraction and cognitive exstimation, ideational and ideomotor praxis test. In agreement with previous studies [11], a cognitive impairment was present in several domains in the pre-implantation phase, particularly in executive functions, memory and attention domain. After implantation the neuropsychological profile showed a significant improvement in the memory domain, while the other cognitive features remained stable compared to the pre-implantation phase.

\section{Discussion}

In the literature, ESHF has been associated with cognitive disorders and it has been suggested that this could depends of the reduced cardiac output [4], from systolic hypotension involving subcortical white matter lesions, reduction of cerebral blood circulation with impact on neuronal oxygenation [12] and neuronal loss, in particularly in hippocampal and para-hippocampal cortex [12] more sensitive to memory processes. LVAD restores a greater cardiac output and it may provide the deficit caused by chronic hypoperfusion.

\section{Limits of the studies}

As affirm by Mapelli et al [19], the scientific literature on the cognitive effects of ESHF patients with CF-LVAD is at an early stage and it shows several limitations. Although there were the amount of data on neuropsychological profile of ESHF patients $[20,21]$ few studies analyze the cognitive profile of the subjects in the pre-implantation stage. In this regard Petrucci et al [10], have analyzed, through a prospective study of eighteen years, the cognitive function of a population during the pretransplant phase stage in different levels of heart failure severity. The final sample was consisted by 252 subjects divided into three sub-groups $(113,83$, including a subgroup of 56 patients due to receive the implantation of a LVAD). The results showed the presence of cognitive deficits in each group, but, as expected, higher deficits were seen in the third sub-group particularly in mental processing speed and memory domain. The results of Mapelli et al [19], despite of the small sample, confirm the neuropsychological profile of the subjects in preimplantation phase.

A further limitation of the cited study is the usual lack of a control group, with the exception of 
Zimpfer et al [16], who included an age-matched healthy control group. None of the study included a control group of ESHF not undergoing LVAD implantation. The presence of a control group with similar clinical status would be necessary to rule out an improvement in neuropsychological performance due to "practice effect" across multiple testing [22].

Moreover these studies did not specified, except for Petrucci et al [17], the cardiac disease underlying ESHF. Different types of heart disease can lead to a different cerebral damage [21] and consequently to a different pre-implantation cognitive level. In the cited study [17] patients did not undergo pre-implantation assessment, therefore the effect of implantation on cognition in difference cardiac diseases cannot be evaluated.

\section{Future perspectives}

In this brief review, we have analyzed only studies in which a complete neuropsychological assessment was perfomed. Moreover, according to Mapelli et al [19], neuropsychological profile should be completed by the assessment of the psychological state, especially because of the hard psychological impact of this procedure on the quality of life. In fact, both psychological state and quality of life might affect deeply cognitive performance, and vice versa.

We have found no differences, in the analyzed literature, between continuous and pulsatile flow on neuropsychological profile.

\section{Conclusions}

From our analysis of the few studies in the literature, ESHF patients seem to show a sustained improvement of the neuropsychological profile after LVAD implantation, independently from continuous or pulsatile flow. Yet further studies are needed who included a pre-implantation assessment, both a short-term and a long-term assessment, an age- and health-matched control group and a careful analysis of cases lost to follow-up. Moreover the influence of pre-implantation condition, the effect of underlying heaert disease and the association between cardiovascular parameters, cognitive profile and psychological status have to be clarified further.

We believe that neuropsychological assessment should be provided to all patients before LVAD implantation and that it is necessary for a proper short and long-term follow-up, at least in a research setting.

\section{Riassunto}

L'incremento dello scompenso cardiaco in fase severa con la conseguente riduzione della disponibilità di organi per i trapianti ha portato, negli ultimi anni, all'introduzione del LVAD come terapia sostitutiva al trapianto cardiaco. I soggetti con scompenso cardiaco in fase severa mostrano deficit cognitivi in vari domini in particolare nelle funzioni esecutive, nella memoria e nella velocità procedurale, dovuti, a diversi processi neurofisiopatologici tra cui l' ipoperfusione cronica e conseguenti danni ad aree corticali ippocampali e para-ippocampali. $\grave{E}$ anche noto che tali deficit migliorano dopo trapianto cardiaco. A tal scopo abbiamo effettuato una rassegna della letteratura selezionando gli studi che analizzano le variazioni cognitive in pazienti con scompenso cardiaco severo dopo l'impianto del device ventricolare a flusso continuo. Sono stati selezionati, in base ai criteri di ricerca, quattro studi dal 2005 ad oggi che presentassero un' analisi neurocognitiva completa dei soggetti arruolati. I risultati mostrano che il profilo cognitivo, con l'impianto di LVAD, migliora nei domini mnesico ed esecutivo e che tale miglioramenti sono stabili nel breve-medio periodo. Gli effetti sarebbero inoltre indipendenti dal tipo di flusso prodotto dai device (pulsatile vs continuo). Ulteriori studi sono comunque necessari per approfondire la relazione tra LVAD e funzione cognitiva nello scompenso cardiaco in fase severa.

Parole chiave: "ventricular assist device", cognitive, neurocognitive, neuropsychology.

\section{References}

1. Catanese KA, Goldstein DJ, Williams DL, et al. Outpatient left ventricular assist device support: a destination rather than a bridge. Ann Thorac Surg 1996; 62: 646-52.

2. Kamdar F, Boyle A, Liao K, et al. Effects of centrifugal, axial, and pulsatile left ventricular assist device support on end-organ function in heart failure patients. $J$ Heart Lung Transplant 2009; 28: 352-9.

3. Puehler T, Ensminger S, Schoenbrodt M, et al. Mechanical circulatory support devices as destination therapy-current evidence. Ann Cardiothorac Surg 2014; 3: 513-524

4. Lietz, K, Brown K, Ali SS, et al. The role of cerebral hyperperfusion in postoperative neurologic dysfunction after left ventricular assist device implantation for endstage heart failure. J Thorac Cardiovasc Surg 2009; 137: 1012-1019.

5. Slaughter MS, Rogers JG, Milano CA, et al. Advanced Heart Failure Treated with Continuous-Flow Left Ventricular Assist Device. N Engl J Med 2009; 361: 2241-2251.

6. Letsou GV, Myers TJ, Gregoric ID, et al. Continuous axial-flow left ventricular assist device (Jarvik 2000) maintains kidney and liver perfusion for up to 6 months. Ann Thorac Surg. 2003; 76: 1167-1170.

7. Radovancevic B, Vrtovec B, de Kort E, et al. End-organ function in patients on long-term circulatory support with continuous- or pulsatile-flow assist devices. J Heart Lung Transplant. 2007; 26: 815-818.

8. Eggermont LH, de Boer K, Muller M, et al. Cardiac disease and cognitive impairment: a systematic review. Heart. 2012; 98: 1334-40.

9. Dew MA, Simmons RG, Roth LH, et al. Psychosocial predictors of vulnerability to distress in the year following heart transplantation. Psychol Med. 1994; 24: 929-45.

10. Petrucci RJ, Truesdell KC, Carter A, et al. Cognitive dysfunction in advanced heart failure and prospective cardiac assist device patients. Ann Thorac Surg 2006; 81: 1738-1744.

11. Pan A, Kumar R, Macey PM, et al. Visual assessment of brain magnetic resonance imaging detects injury to cognitive regulatory sites in patients with heart failure. J Card Fail 2013; 19: 94-100.

12. Woo MA, Kumar R, Macey PM, et al. Brain injury in autonomic, emotional, and cognitive regulatory areas in patients with heart failure. J Card Fail 2009; 15(3): 214-223. 
13. Corrà U, Pistono M, Mezzani A, et al. Cardiovascular prevention and rehabilitation for patients with ventricular assist device from exercise therapy to long-term therapy. Part I: Exercise therapy. Monaldi Arch Chest Dis. 2011 Mar; 76(1): 27-32.

14. Marko C, Danzinger G, Käferbäck M, et al. Safety and efficacy of cardiac rehabilitation for patients with continuous flow left ventricular assist devices. Eur J Prev Cardiol. 2014 Nov 7. pii: 2047487314558772

15. Fattirolli F, Bonacchi M, Burgisser C, et al. Cardiac Rehabilitation of patients with left ventricular assist device as "Destination therapy". Monaldi Arch Chest Dis 2009; 72: 190-199.

16. Zimpfer D, Weiselthaler G, Czerny M, et al. Neurocognitive function in patients with ventricular assist devices: A comparison of pulsatile and continuous blood flow device, ASAIO Journal 2006; 52: 24-27.

17. Petrucci RJ, Wright S, Naka Y, et al. Neurocognitive assessment in advanced heart failure patients receiving con- tinuous-flow left ventricular assist devices. J Heart Lung Transplant 2009; 28 (6): 542-549.

18. Petrucci RJ, Rogers JG, Blue L, et al. Neurocognitive function in destination therapy patients receiving continuous-flow vs pulsative-flow left ventricular assist device support. J Heart Lung Transplant 2012; 31: 27-36.

19. Mapelli D, Cavazzana A, Cavalli C, et al. Clinical psychological and neuropsychological issues with left ventricular assist device (LVADs). Ann Cardiothorac Surg 2014; 3(5): 480-489.

20. Vogels RL, Scheltens P, Schroeder-Tanka JMREF, et al. Cognitive impairment in heart failure: a systematic review of the literature. Eur J Heart Fail 2007; 9(5): 440-449.

21. Gaviria M, Pliskin N, Kney A. Cognitive impairment in patients with advanced heart failure and its implications on decision-making capacity. Congest Heart Fail 2011; 17(4): 175-9.

22. Francis GS, Tang WH. Pathophysiology of congestive heart failure. Rev Cardiovasc Med. 2003; 4 Suppl 2: S14-20. 